\title{
Pelaksanaan trias usaha kesehatan sekolah (UKS) di sekolah dasar
}

\author{
Leni Apriani ${ }^{1}$, Novri Gazali ${ }^{1}$ * \\ ${ }^{1}$ Jurusan Pendidikan Jasmani Kesehatan dan Rekreasi, Fakultas Keguruan dan Ilmu Pendidikan, \\ Universitas Islam Riau. Jl. Kaharuddin Nasution No. 113, Marpoyan Damai, Pekanbaru, Indonesia \\ * Corresponding Author. Email: novri.gazali@edu.uir.ac.id \\ Received: 13 June 2017; Revised: 8 February 2018; Accepted: 1 March 2018
}

\begin{abstract}
Abstrak
Penelitian ini bertujuan untuk mengetahui pelaksanaan Trias UKS di Sekolah Dasar Negeri Gugus II Bukit Raya Kota Pekanbaru. Jenis penelitian yang digunakan adalah metode deskriptif. Populasi dalam penelitian ini adalah seluruh siswa kelas V SD Gugus II Bukit Raya Kota Pekanbaru sebanyak 118 orang. Sampel dalam penelitian ini diambil dengan cara total sampling yang berjumlah 118 orang. Instrumen dalam penelitian ini menggunakan angket yang dibuat berdasarkan buku pedoman untuk tenaga kesehatan usaha kesehatan sekolah. Teknik analisis data menggunakan analisis deskriptif, sedangkan perhitunganya menggunakan persentase. Untuk mengetahui kriteria dalam pensekoran data tiap faktor maka dilakukan pengkategorian, sesuai dengan instrumen, yaitu: sangat baik, baik, cukup baik dan tidak baik. Berdasarkan hasil penelitian dari 5 sekolah maka dapat disimpulkan pelaksanaan program usaha kesehatan sekolah (UKS) di Sekolah Dasar Negeri Gugus II Bukit Raya Kota Pekanbaru secara keseluruhan berkategori kurang baik. Hal ini dapat dilihat dari tiga aspek, yaitu: (1) aspek lingkungan kehidupan sekolah yang sehat dengan kategori cukup, (2) aspek pendidikan atau penyuluhan di sekolah dengan kategori kurang baik, (3) aspek pelayanan kesehatan di sekolah dengan kategori kurang baik.
\end{abstract}

Kata Kunci: pelaksanaan, trias UKS, sekolah dasar

\section{The implementation of trias school health unit (Trias UKS) at primary school}

\begin{abstract}
This research aims to know the implementation of the trias UKS in elementary school the country Cluster II Bukit Raya Pekanbaru. This type of research method used is descriptive. The population in this research is the whole grade V SD Cluster II Bukit Raya as much as 118 people. The sample in this study is taken by way of sampling a total of 118 people. Technique of data analysis using descriptive analysis, while the calculation using percentage. To know the criteria in data scoring each factor then done categorization, in accordance with the instrument, namely: very good, good, good enough and not good. Based on the results of research from 5 schools it can be concluded the implementation of the program school health (UKS) in State Elementary School Gugus II Bukit Raya Pekanbaru as a whole is categorized less good. This can be seen from three aspects, : (1) environmental aspects of healthy school life with sufficient category, (2) aspects of education or counseling in schools with less good category, (3) aspects of health services in schools with less good category.
\end{abstract}

Keywords: implementation, trias UKS, primary education

How to Cite: Apriani, L., \& Gazali, N. (2018). Pelaksanaan trias usaha kesehatan sekolah (UKS) di sekolah dasar. Jurnal Keolahragaan, 6(1), 20-28. doi:http://dx.doi.org/10.21831/jk.v6i1.14456

http://dx.doi.org/10.21831/jk.v6i1.14456 


\section{PENDAHULUAN}

Perilaku hidup sehat merupakan kebiasaan yang butuh ketelatenan dalam penanaman pada setiap anak dan harus dimulai sedini mungkin. Seluruh lapisan masyarakat berhak hidup sehat dan mendapatkan pelayanan kesehatan yang layak serta ikut berperan aktif dalam pembangunan kesehatan. Hidup sehat dan mendapatkan pelayanan kesehatan yang memadai juga berhak didapatkan oleh seluruh anak Indonesia ketika menempuh jenjang pendidikan, mereka pun diharapkan ikut berperan aktif dalam melaksanakan pembangunan kesehatan. Untuk itu, salah satu bidang yang terpenting adalah bidang kesehatan sekolah. Salah satu usaha yang dilakukan dan terus dikembangkan adalah usaha kesehatan sekolah atau yang disebut dengan UKS.

Salah satu bidang pendidikan nasional untuk program UKS dilaksanakan pada semua jenis dan tingkat pendidikan, baik sekolah negeri maupun sekolah swasta mulai tingkat sekolah dasar (SD) hingga sekolah menegah atas (SMA). Berdasarkan Pokok Kebijaksanaan Pembinaan dan Pengembangan UKS dan Tim Pembina UKS yang telah ditetapkan oleh pemerintah, UKS memiliki tiga program utama yang dikenal dengan Trias UKS. Ketiga program tersebut yakni, pertama: pendidikan kesehatan, yang meliputi pengetahuan dan pemahaman mengenai cara memelihara dan meningkatkan kesehatan, kedua: pelayanan kesehatan, yang meliputi pengobatan ringan. dan ketiga: lingkungan sekolah sehat yang meliputi pembinaan dan pemeliharaan kesehatan lingkungan seperti pelaksanaan 7K (kebersihan, keindahan, kenyamanan, ketertiban, keamanan, kerindangan, kekeluargaan). (Praditya \& Nasution, 2016, p. 42).

UKS memiliki manfaat langsung terhadap peningkatan kesehatan anak sekolah, dan memiliki potensi besar dalam penyuksesan program peningkatan derajat kesehatan secara lebih luas. Oleh karena itulah UKS dapat digunakan sebagai wadah sekaligus kendaraan yang dapat digunakan oleh berbagai program kesehatan, seperti kesehatan ibu dan anak, gizi, pemberantasan penyakit menular (P2M), kesehatan lingkungan, pengobatan, dan promosi kesehatan.

Sekolah merupakan sebuah lembaga formal, tempat anak didik memperoleh pendidikan dan pelajaran yang diberikan oleh guru. Sekolah mempersiapkan anak didik memperoleh ilmu pengetahuan dan keterampilan, agar mampu berdiri sendiri dalam masyarakat. Di dalam memajukan pengembangan nasional, anak merupakan investasi pembangunan dalam bidang tenaga kerja dan pewaris negara di masa depan, maka pembinaan terhadap anak perlu dimulai sejak dini. Sehubungan dengan itu, bidang pendidikan dan kesehatan mempunyai peranan yang besar karena secara organisatoris sekolah berada di bawah Departemen Pendidikan Nasional, sedangkan secara fungsional Departemen Kesehatan bertanggung jawab atas kesehatan anak didik (Poernomo, Suharto, \& Siswanto, 2002, pp. 16-17).

Program pendidikan kesehatan di sekolah untuk saat ini tidak tersedia waktu khusus, sehingga menjadi kendala tersendiri bagi para guru maupun petugas dalam melaksanakan pendidikan kesehatan padahal pendidikan kesehatan melalui anak-anak sekolah sangat efektif untuk mengubah perilaku dan kebiasaan hidup sehat umumnya. Di sisi lain, program pelayanan kesehatan sekolah saat ini hanya dilaksanakan ala kadarnya, sebagaimana yang terlihat bahwa di sekolah dasar banyak yang tidak memiliki ruang UKS. Selama ini apabila ada siswa yang membutuhkan pertolongan pertama hanya ditempatkan di ruang guru. Begitu juga dengan peralatan dan perlengkapan lainnya belum mendapat perhatian. Selain itu kemampuan dan pengetahuan guru penjas ataupun pengelola UKS yang masih kurang juga memengaruhi pelayanan kesehatan kepada siswa.

Kondisi lingkungan sekolah yang sehat juga mempunyai peran dalam terciptanya kebiasaan peserta didik untuk beperilaku hidup sehat. Meskipun demikian, pembinaan lingkungan sekolah sehat melalui pemeliharaan sarana fisik dan lingkungan sekolah belum optimal, seperti belum tersedianya sarana sekolah yang mendukung terciptanya lingkungan yang bersih dan sehat, kemudian belum dilakukan penataan halaman, pekarangan, apotek hidup dan pasar sekolah yang aman. Meskipun demikian, dengan semua keterbatasan yang kompleks hendaknya pelaksanaan program UKS pada sekolah harus tetap diupayakan seoptimal mungkin. Hal ini disebabkan anak merupakan modal bangsa yang sangat penting sebagai generasi penerus bangsa dan SD merupakan tonggak utama dalam pendidikan terhadap anak untuk melanjutkan ke tingkat pendidikan yang lebih tinggi.

Pelaksanaan Trias UKS SD se-Gugus II Bukit Raya Kota Pekanbaru masih sangat kurang. Hampir semua SD belum bersungguh- 
sungguh dalam melaksanakan UKS secara terencana dan terarah. Selain itu sebagian sekolah belum mampu mengorganisasi UKS dengan baik, belum ada kerja sama yang baik dengan pihak-pihak yang terkait, misal Dinas Kesehatan, Dinas Pendidikan Nasional, orang tua siswa, dan organisasi lainnya, sehingga terkesan bahwa kesehatan anak didik adalah tanggung jawab orang tua semata. Untuk itu keaktifan pihakpihak lain sangat diperlukan untuk kelancaran pelaksanaan UKS.

Di era globalisasi ini, ada tuntutan bagi setiap sekolah untuk mempunyai kegiatan UKS, karena dengan adanya UKS diharapkan mampu memenuhi pendidikan kesehatan secara terstruktur dan terencana dengan baik sehingga tercipta lingkungan yang sehat di sekolah dalam rangka meningkatkan mutu pendidikan dan prestasi belajar peserta didik.

Dolores dan Habibie, (2016, p42) menyatakan usaha kesehatan sekolah (UKS) adalah merupakan sebuah wahana pelayanan, pendidikan dan pembinaan kesehatan yang ada di sekolah. Pembinaan dan pengembangan UKS merupakan salah satu upaya meningkatkan derajat kesehatan yang ditujukan kepada peserta didik (usia sekolah), yang merupakan salah satu bentuk usaha dalam meningkatkan kualitas fisik manusia.

Trisnowati \& Moekarto (2007, p. 560) menyatakan, "Usaha Kesehatan Sekolah (UKS) adalah suatu usaha untuk meningkatkan kemampuan derajat hidup sehat peserta didik sedini mungkin, yang dilakukan secara terpadu oleh empat departemen terkait beserta seluruh jajaranya, baik di tingkat pusat mapun daerah."

Dari pendapat tersebut, dapat dijelaskan bahwa UKS adalah upaya pendidikan untuk meningkatkan derajat kesehatan peserta didik sejak usia dini yang dilaksanakan di sekolah. Artinya, pada setiap jenjang pendidikan dilaksanakan kegiatan UKS agar lebih terarah dan berkesinambungan.

Tujuan UKS adalah untuk meningkatkan kemampuan hidup sehat dan derajat kesehatan peserta didik sedini mungkin. Tujuan umum UKS adalah untuk meningkatkan kemampuan hidup sehat dan derajat kesehatan peserta didik serta menciptakan lingkungan yang sehat (Mukminin \& Tasu'ah, 2016, p. 12). Hal ini memungkinkan pertumbuhan dan perkembangan yang harmonis dan optimal dalam rangka pembentukan manusia Indonesia seutuhnya. Setiap organisasi, apa pun bentuknya memiliki tujuan-tujuan yang ingin dicapai. Begitu juga halnya dengan UKS.

Dengan adanya program UKS, anak didik akan lebih baik lagi dalam menerima pembelajaran, dikarenakan anak didik dalam keadaan yang sehat. Di sini dapat dilihat betapa pentingnya peranan UKS dalam dunia pendidikan untuk menghasilkan mutu pendidikan yang lebih baik.

Untuk mewujudkan program UKS, aspek penting yang harus diperhatikan adalah sumber daya manusia yang berkualitas, untuk menciptakan sumber daya manusia yang berkualitas harus dimiliki suatu pengetahuan yang baik (Sitepu, Ratag, \& Siagian, 2015, p. 35). Dalam mewujudkan program UKS, haruslah dimiliki pelaksana UKS.

Pelaksana UKS ialah seseorang yang berdasarkan fungsi, tugas, dan kewajibanya berhubungan dengan anak didik dan lingkungan sekolah. Petugas UKS biasa dilakukan oleh seorang guru sebagai pembina dari UKS dan anak didik yang melaksanakan tugas dan menjaga UKS yang biasanya dibimbing oleh guru di sekolah.

Menurut Hasan \& Alatas (2005, p. 61) di samping sebagai petugas kesehatan, guru mempunyai peranan yang sangat penting di dalam pelaksanaan UKS, mengingat bahwa gurulah yang setiap hari menghadapi anak didik dan mengikuti pertumbuhan, perkembangan, dan keadaan kesehatan anak didiknya. Peranan para pelaksana UKS meliputi:

\section{Peranan Petugas Kesehatan}

Petugas kesehatan yang melaksanakan kegiatan UKS meliputi pemberian bimbingan kepada guru dalam menjalankan usaha kesehatan di sekolah, membantu guru dalam kegiatan pengawasan kesehatan perorang dan lingkungan, pemeriksaan kesehatan, imunisasai, memberikan pendidikan kesehatan secara langsung dan tidak langsung kepada anak didik, memupuk kerja sama yang baik antara semua unsur yang diberikan guru untuk diolah lebih lanjut.

\section{Peranan Guru}

Peranan guru dalam menjalankan program UKS di antaranya ialah menanamkan kebiasaan hidup sehat kepada anak didiknya, pemeriksaan dan pengawasan kebersihan perorangan dan lingkungan, mengenal kelainan peserta didik yang mungkin terdapat (jasmani dan rohani), pembinaaan kebugaran jasmani, membimbing murid melakukan gerakan terampil dan efektif untuk segala aktivitasnya, termasuk pemupukan 
bakat di bidang keolahragaan, menjalankan P3K dan pengobatan ringan dalam batas kemampuannya dan jika perlu mengirimkan ke poliklinik terdekat, mengenal tanda penyakit menular beserta masalah dan tindakan selanjutnya (misalnya melarang murid yang menderita sakit cacar air, campak, baruk rejan, gondongan dan lain-lain, masuk sekolah), menjadi teladan bagi muridnya, membuat catatan tentang kegiatan UKS, membantu petugas kesehatan dalam tugasnya di sekolah.

\section{Peranan Anak Didik}

Anak didik atau murid ialah anggota masyarakat sekolah yang dapat memengaruhi lingkunganya. Peranan anak didik: (a) memilihara kebersihan diri, (b) menaati segala nasihat guru dan petugas kesehatan dalam hubungannya dengan usaha pemeliharaan badan dan pakaiannya, (c) menyukai dan menghargai makanan yang mempunyai nilai gizi tinggi, (d) menjadi penghubung bagi masyarakat dalam hal menanamkan kebiasaan hidup sehat, (e) menjadi contoh bagi anak-anak lain di luar sekolah, dalam berlaku hidup sehat.

\section{Peranan Orang Tua Murid}

Lingkungan rumah berpengaruh besar dalam pertumbuhan dan perkembangan anak, sehingga diperlukan bantuan yang aktif. Peranan orang tua murid di antaranya ialah: (a) berusaha mempelajari apa yang didapat oleh anaknya di sekolah dalam bidang kesehatan, (b) turut serta mengawasi agar anak-anaknya melakukan kebiasaan hidup yang sehat, (c) turut serta secara aktif dalam pelaksana UKS, (d) dapat memberikan sumbangan tenaga, dana, dan pikiran demi kelangsungan dan tercapainya pendidikan (UKS).

\section{Ruang Lingkup Pembinaan UKS}

Poernomo (1979, p. 30) menyatakan program UKS meliputi tiga program utama yaitu: (1) lingkungan kehidupan sekolah yang sehat, (2) pendidikan atau penyuluhan kesehatan, dan (3) pelayanan kesehatan di sekolah, yang selanjutnya lebih dikenal dengan istilah Trias Program UKS.

\section{Lingkungan Kehidupan Sekolah yang Sehat}

Hal ini merupakan dasar dan faktor yang besar pengaruhnya terhadap pertumbuhan dan perkembangan jasmani, rohani, dan sosial anak didik dan penghuni lainya di sekolah. Lingkungan kehidupan sekolah yang sehat merupa- kan satu unsur yang harus ada, dibina, dan dikembangkan terus agar pendidikan mencapai hasil yang diharapkan. Menurut Trisnowati \& Moekarto (2007, p. 51) beberapa hal yang perlu diperhatikan terkait dengan lingkungan kehidupan sekolah yang sehat yaitu: (a) pemeliharaan kebersihan, (b) perorangan dan lingkungan, (c) WC dan kamar mandi, (d) persediaan air, (e) tempat sampah dan pembuangan sampah, dan (f) ruang-ruang lain.

\section{Pendidikan atau Penyuluhan Kesehatan}

Soenarjo (2008, p. 40) menyatakan pendidikan atau penyuluhan kesehatan meliputi: (a) kebersihan badan dan kulit, (b) kebersihan kepala dan rambut, dan (c) kebersihan alat-alat indra.

\section{Pelayanan Kesehatan di Sekolah}

Pelayanan kesehatan di sekolah merupakan salah satu program Trias UKS. Tujuanya ialah: (a) mengikuti pertumbuhan dan perkembangan anak didik, (b) mengetahui kelainan atau gangguan kesehatan sedini mungkin, (c) pencegahan penyakit menular, (d) pengobatan secepat-cepatnya, dan (e) pelayanan kesehatan di sekolah yang meliputi segi-segi fisik, mental, dan sosial.

\section{METODE}

Jenis penelitian yang digunakan dalam penelitian ini adalah metode deskriptif. Deskriptif adalah salah satu jenis metode penelitian yang berusaha mengambarkan dan menginterprestasikan objek sesuai dengan apa adanya tanpa bermaksud membuat kesimpulan yang berlaku untuk umum atau generalisasi (Sugiyono, 2010, pp. 207-208). Tujuan utama metode ini adalah menggambarkan suatu keadaan yang dalam hal ini tentang pelaksanaan program Trias UKS di SD Negeri Gugus II Bukit Raya Kota Pekanbaru.

Penelitian ini dilaksanakan di SD Negeri Gugus II Bukit Raya Kota Pekanbaru, yang terdiri atas lima SD Negeri yaitu SD Negeri 43 Pekanbaru, SD Negeri 76 Pekanbaru, SD Negeri 129 Pekanbaru, SD Negeri 108 Pekanbaru, SD Negeri 180 Pekanbaru. Penelitian dimulai pada tanggal 20 Mei 2016 s.d. 25 Agustus 2016.

Populasi dalam penelitian ini adalah seluruh siswa kelas VI SD Negeri Gugus II Bukit Raya Kota Pekanbaru sebanyak 153 orang. Sampel dalam penelitian ini diambil dengan cara total sampling. Karena penelitian ini merupakan penelitian deskriptif, dibutuhkan subjek penelitian yang banyak, sehingga 
keseluruhan populasi dalam penelitian dijadikan sampel.

Instrumen penelitian menurut Sugiyono (2010, p. 148) adalah alat ukur yang digunakan untuk mengukur variabel penelitian yang diamati. Instrumen yang diperlukan agar pekerjaan yang dilakukan lebih mudah dan hasilnya lebih baik, dalam arti lebih cermat, lengkap, dan sistematis sehingga data lebih mudah diolah, dalam penelitian ini digunakan angket yang dibuat berdasarkan buku pedoman untuk tenaga kesehatan usaha kesehatan sekolah. Dalam penelitian ini angket disajikan dalam lima alternatif jawaban yaitu Selalu $(\boldsymbol{S L})$, Sering (S), Kadang-Kadang (KD), Hampir Tidak Pernah (HTP), Tidak Pernah (TP), dengan skor $\mathrm{SL}=1, \mathrm{~S}=2, \mathrm{KD}=3, \mathrm{HTP}=4, \mathrm{TP}=5$ untuk setiap butir pertanyaan.

Langkah-langkah dalam menyusun angket menurut Hadi (1991, p. 7) adalah mendefinisikan konstrak, menyidik faktor, dan menyusun butir pertanyaan.

Mendefinisikan Konstrak (Construct Definition) yaitu membuat batasan terhadap variabel atau konstrak yang akan kita ukur sehingga nantinya tidak akan terjadi penyimpangan terhadap tujuan yang ingin dicapai dalam penelitian.

Menyidik Faktor (Identification of Factor) merupakan langkah untuk menentukan unsur-unsur yang relevan dengan variabel berdasarkan konstrak yang telah ditetapkan, sehingga akhirnya akan terdapat faktor-faktor yang mejadi titik konsentrasi dalam penelitian. Berdasarkan konstrak yang diteliti, program Trias UKS merupakan titik konsentrasi dalam penelitian ini. Adapun faktor-faktor tersebut sebagai berikut:

Pendidikan Kesehatan, dengan indicatorindikator sebagai berikut (1) kebersihan perorangan dan lingkungan; (2) pencegahan dan pemberantasan penyakit menular; (3) gizi dan makanan; (4) pencegahan kecelakaan dan PPPK

Pelayanan Kesehatan, dengan indicatorindikator sebagai berikut (1) mengetahui pertumbuhan dan gangguan kesehatan sedini mungkin; (2) pencegahan penyakit menular; (3) usaha di bidang gizi; (4) pembinaan lingkungan sekolah sehat; (5) bangunan sekolah dan lingkungan; (6) pemeliharaan kebersihan perorangan dan lingkungan; dan (6) keamanan umum di sekolah dan lingkungannya.

Menyusun Butir-Butir Pernyataan (Item Conctruction). Menyusun butir-butir pernyataan haruslah berbicara mengenai faktornya saja, tidak membicarakan faktor yang lain. Untuk mengungkap gambaran yang tersedia selengkapnya mengenai instrumen yang digunakan dalam penelitian ini, diperlukan pula kisi-kisi. Adapun kisi-kisi instrumen penelitian pelaksanaan program Trias UKS yang digunakan dalam penelitian ini dapat dilihat pada Tabel 1.

Tabel 1. Kisi-Kisi Instrumen Pelaksanaan Trias UKS di Sekolah Dasar Negeri Gugus II Bukit Raya Kota Pekanbaru

\begin{tabular}{clcc}
\hline Variabel & \multicolumn{1}{c}{ Indikator } & $\begin{array}{c}\text { Item } \\
\text { Soal }\end{array}$ & Jumlah \\
\hline & $\begin{array}{l}\text { Lingkungan } \\
\text { kehidupan sekolah }\end{array}$ & $1-10$ & 10 \\
Trias UKS & $\begin{array}{l}\text { yang sehat } \\
\text { Pendidikan atau }\end{array}$ & & \\
$\begin{array}{c}\text { (3 Program } \\
\text { UKS) }\end{array}$ & $\begin{array}{l}\text { penyuluhan } \\
\text { kesehatan }\end{array}$ & $11-20$ & 10 \\
& $\begin{array}{l}\text { Pelayanan kesehatan } \\
\text { di sekolah }\end{array}$ & $21-30$ & 10 \\
& Jumlah & $\mathbf{3 0}$ & $\mathbf{3 0}$ \\
\hline
\end{tabular}

\section{Teknik Analisis Data}

Teknik analisis data menggunakan analisis deskriptif, sedangkan perhitunganya menggunakan persentase. Menurut Sudijono (2005, p. 175) untuk menghitung frekuensi relatif (\%) menggunakan rumus sebagai berikut:

$P=\frac{\mathbf{F}}{\mathbf{N}} x \mathbf{1 0 0} \%$

Keterangan:

$\mathrm{P}=$ Persentase

$\mathrm{F}=$ Frekuensi

$\mathrm{N}=$ Jumlah Responden

Dalam menentukan kriteria dilakukan pengelompokan atas empat kriteria penilaian yaitu sangat baik, baik, cukup baik, dan tidak baik. Hal ini mengacu pada kriteria persentase sebagai berikut: (1) Persentase antara $76 \%$ s.d. $100 \%$ dikatakan "Baik"; (2) Persentase antara 56\% s.d. 75\% dikatakan "Cukup"; (3) Persentase antara $40 \%$ s.d. 55\% dikatakan Kurang Baik"; dan (4) Persentase kurang dari $40 \%$ dikatakan "Tidak Baik".

\section{HASIL DAN PEMBAHASAN}

\section{Deskriptif Data}

Kuesioner menggunakan skala Guttman, peneliti mengambil pilihan YA dan TIDAK. Dari pernyataan yang ada, jawaban positif mendapatkan skor 1 dan jawaban negatif mendapatkan skor 0 . 
Pelaksanaan Program Trias UKS SD Negeri 45 Bukit Raya

Berdasarkan tujuh pernyataan pada aspek lingkungan kehidupan sekolah yang sehat terdapat nilai rata-rata 4,5 ; tujuh pernyataan pendidikan atau penyuluhan di sekolah terdapat nilai rata-rata 3,54; dan tujuh pernyataan pelayanan kesehatan di sekolah terdapat nilai rata-rata 3,33 diperoleh hasil seperti Gambar 1.

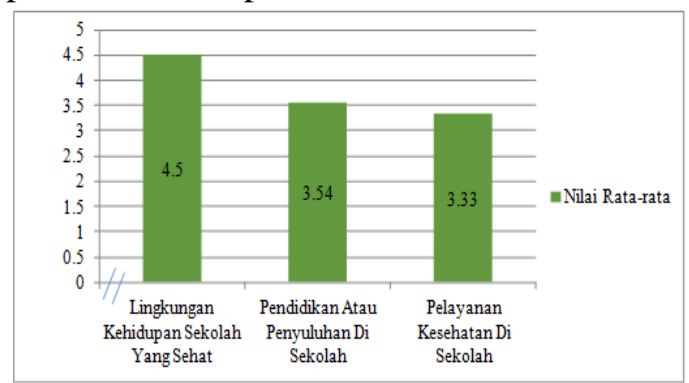

Gambar 1. Pelaksanaan Program Trias UKS SD Negeri 45 Bukit Raya

Pelaksanaan Program Trias UKS SD Negeri 129 Bukit Raya

Berdasarkan tujuh pernyataan pada aspek lingkungan kehidupan sekolah yang sehat terdapat nilai rata-rata 4,45 ; tujuh pernyataan pendidikan atau penyuluhan di sekolah terdapat nilai rata-rata 3,55; dan tujuh pernyataan pela-yanan kesehatan di sekolah terdapat nilai rata-rata 3,23 diperoleh hasil seperti Gambar 2.

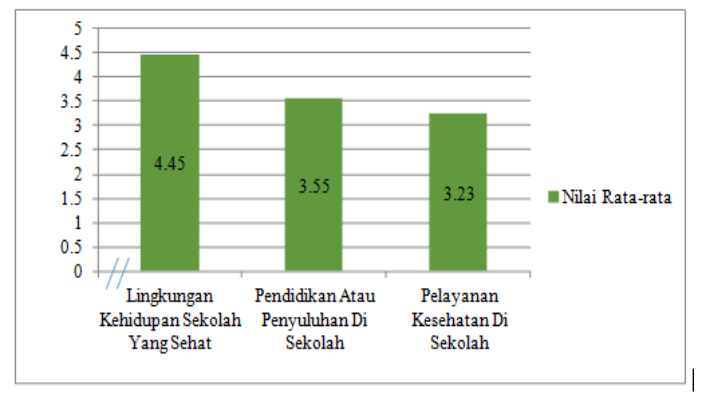

Gambar 2. Pelaksanaan Program Trias UKS SD Negeri 129 Bukit Raya

Pelaksanaan Program Trias UKS SD Negeri 180 Bukit Raya

Berdasarkan tujuh pernyataan pada aspek lingkungan kehidupan sekolah yang sehat terdapat nilai rata-rata 4,46; tujuh pernyataan pendidikan atau penyuluhan di sekolah terdapat nilai rata-rata 3,54; dan tujuh pernyataan pelayanan kesehatan di sekolah terdapat nilai ratarata 3,19 diperoleh hasil seperti Gambar 3.

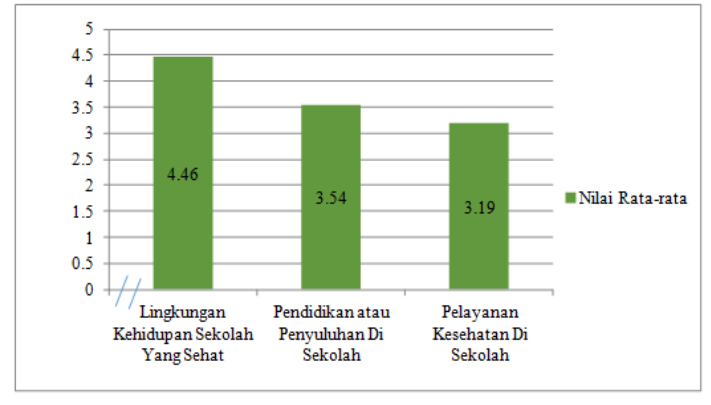

Gambar 3. Pelaksanaan Program Trias UKS SD Negeri 180 Bukit Raya

Pelaksanaan Program Trias UKS SD Negeri 108 Bukit Raya

Berdasarkan tujuh pernyataan pada aspek lingkungan kehidupan sekolah yang sehat terdapat nilai rata-rata 4,61; tujuh pernyataan pendidikan atau penyuluhan di sekolah terdapat nilai rata-rata 4,09; dan tujuh pernyataan pelayanan kesehatan di sekolah terdapat nilai ratarata 4,04 diperoleh hasil seperti Gambar 4.

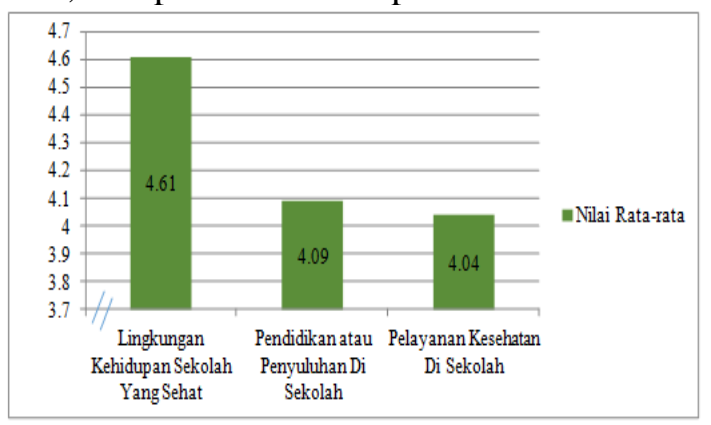

Gambar 4. Pelaksanaan Program Trias UKS SD Negeri 108 Bukit Raya

Pelaksanaan Program Trias UKS SD Negeri 76 Bukit Raya

Berdasarkan tujuh pernyataan pada aspek lingkungan kehidupan sekolah yang sehat terdapat nilai rata-rata 3,83 ; tujuh pernyataan pendidikan atau penyuluhan di sekolah terdapat nilai rata-rata 3,52; dan tujuh pernyataan pelayanan kesehatan di sekolah terdapat nilai rata-rata 3,48 diperoleh hasil seperti Gambar 5.

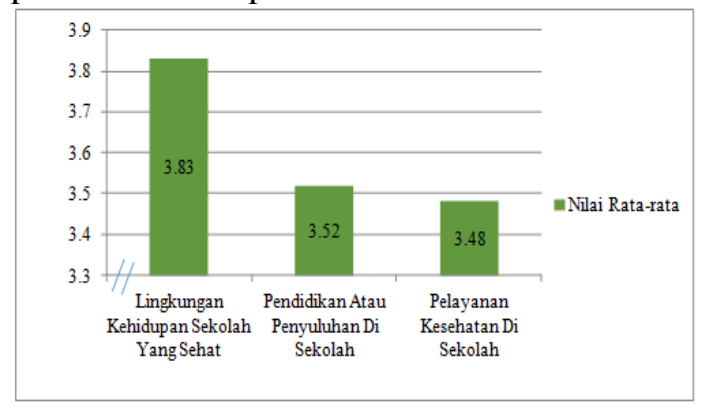

Gambar 5. Pelaksanaan Program Trias UKS SD Negeri 76 Bukit Raya 


\section{Rekapitulasi Data}

Setelah dijabarkan hasil tiap-tiap data berdasarkan aspek lingkungan kehidupan sekolah yang sehat, pendidikan atau penyuluhan di sekolah, dan pelayanan kesehatan di sekolah, berikut merupakan hasil rekapitulasi data yang diperoleh setiap aspeknya.

Tabel 2. Rekapitulasi Pelaksanaan Program Trias UKS di SD Negeri Gugus II Bukit Raya Kota Pekanbaru

\begin{tabular}{|c|c|c|c|c|c|}
\hline \multirow{2}{*}{ No. } & \multirow{2}{*}{ Aspek } & \multicolumn{2}{|c|}{ Penilaian } & \multirow{2}{*}{$\mathbf{P}$} & \multirow{2}{*}{$\mathbf{K}$} \\
\hline & & $\mathbf{S}$ & SM & & \\
\hline 1. & $\begin{array}{l}\text { Lingkungan kehidupan } \\
\text { sekolah yang sehat }\end{array}$ & 516 & 826 & $62,46 \%$ & Cukup \\
\hline 2. & $\begin{array}{l}\text { Pendidikan atau } \\
\text { penyuluhan di sekolah }\end{array}$ & 430 & 826 & $52,05 \%$ & $\begin{array}{l}\text { Kurang } \\
\text { Baik }\end{array}$ \\
\hline 3. & $\begin{array}{l}\text { Pelayanan kesehatan di } \\
\text { sekolah }\end{array}$ & 407 & 826 & $49,27 \%$ & $\begin{array}{l}\text { Kurang } \\
\text { Baik }\end{array}$ \\
\hline & Jumlah & 1,35 & 2,48 & 54,59 & $\begin{array}{l}\text { Kurang } \\
\text { Baik }\end{array}$ \\
\hline
\end{tabular}

Dari Tabel 2 diketahui aspek lingkungan kehidupan sekolah yang sehat mendapatkan persentase paling tinggi yaitu $62,46 \%$ dengan kategori cukup, pendidikan atau penyuluhan di sekolah mendapatkan persentase rendah yaitu $52,05 \%$ dengan kategori kurang baik, dan pelayanan kesehatan di sekolah mendapatkan persentase paling rendah yaitu $49,27 \%$ dengan kategori kurang baik. Hal itu dapat dilihat pada Gambar 6.

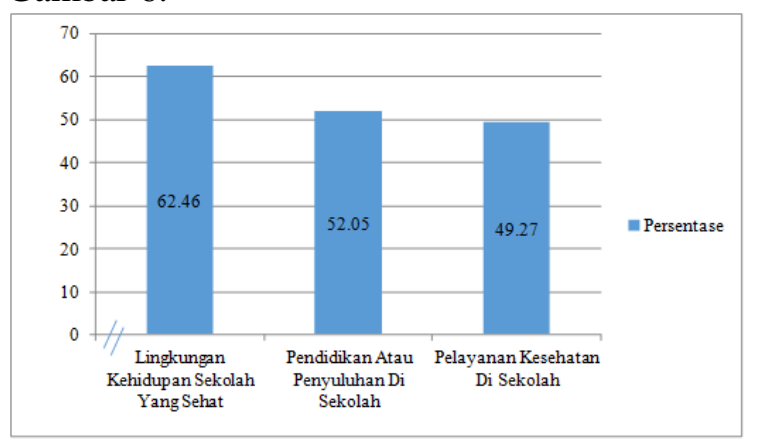

Gambar 6. Pelaksanaan Program Trias UKS SD Negeri Gugus II Bukit Raya

\section{Analisis Data}

Untuk memudahkan pengolahan data, setiap data dihitung dalam bentuk persentase berdasarkan data dan informasi yang diperoleh dalam penelitian tentang pelaksanaan program Trias UKS di SD Negeri Gugus II Bukit Raya Kota Pekanbaru. Hasilnya dapat diketahui berdasarkan perhitungan berikut:

$$
\begin{aligned}
P & =\frac{1353}{2478} \times 100 \% \\
& =54,59 \%
\end{aligned}
$$

Didapatkan nilai secara keseluruhan dari pelaksanaan program Trias UKS di SD Negeri Gugus II Bukit Raya Kota Pekanbaru sebesar $54,59 \%$ dengan kategori kurang baik.

\section{Pembahasan}

Hasil penelitian membuktikan bahwa pelaksanaan program Trias UKS di SD Negeri Gugus II Bukit Raya Kota Pekanbaru secara keseluruhan berkatagori kurang baik. Hal tersebut dinilai berdasarkan tiga program pokok UKS yaitu:

\section{Lingkungan Kehidupan Sekolah Yang Sehat}

Pembinaan lingkungan sekolah sehat di SD Negeri Gugus II Bukit Raya Kota Pekanbaru menunjukkan hasil yakni dari 5 sekolah memperoleh kategori cukup. Dalam pembinaan lingkungan sekolah, kurangnya fasilitas seperti tempat cuci tangan, kurangnya pengawasan terhadap kantin/warung sekolah secara rutin yang mana kebanyakan kantin yang ada kurang memperhatikan kebersihan. Hal ini menyebabkan siswa akan mudah terserang penyakit misalnya sakit perut. Kurangnya poster tentang kebersihan, bahaya rokok, dan lainnya. Namun ada salah satu sekolah yang merupakan sekolah dengan pembinaan lingkungan sekolah sehat yang cukup baik. Sekolah ini memiliki tempat cuci tangan di setiap depan kelas, kamar mandi/ WC yang memadai dan bersih, adanya posterposter mengenai lingkungan bersih, bahaya merokok, bahaya narkoba, adanya penghijauan, ada tempat sampah di tiap kelas, adanya taman/kebun sekolah.

\section{Pendidikan Atau Penyuluhan Kesehatan}

Pelaksanaan pendidikan kesehatan di SD Negeri Gugus II Bukit Raya Kota Pekanbaru menunjukkan hasil yakni dari 5 sekolah memperoleh kategori kurang sekali. Hal ini disebabkan karena kurang aktifnya guru pembina UKS, buku pegangan tentang pendidikan kesehatan sangat sedikit, tidak adanya media pendukung pendidikan kesehatan seperti poster, tidak adanya kegiatan ekstrakurikuler misalnya seperti palang merah remaja, dan sudah sangat jarangnya pihak puskesmas/dinas kesehatan mengadakan kegiatan penyuluhan mengenai bahaya narkoba, minum-minuman keras, dan seks bebas.

\section{Pelayanan Kesehatan di Sekolah}

Pelaksanaan pelayanan kesehatan yang ada di SD Negeri Gugus II Bukit Raya Kota 
Pekanbaru menunjukkan hasil yakni dari 5 sekolah memperoleh kategori kurang sekali. Hal ini disebabkan ada sekolah yang tidak melakukan penjaringan kesehatan, kurangnya pengawasan terhadap penjaja makanan di sekitar sekolah, kurangnya kader kesehatan remaja yang terlatih. Selain itu, pelayanan kesehatan di sekolah sudah bekerja sama dengan puskesmas atau rumah sakit terdekat namun masih kurang maksimal, yang mana instansi seperti puskesmas hanya melakukan penyuluhan kesehatan hanya sekali dalam 1 tahun. Untuk meningkatkan pelayanan kesehatan ini kerjasama dari instansi seperti puskesmas harus lebih ditingkatkan.

Hasil penelitian ini menunjukkan bahwa pelaksanaan program Trias UKS di SD Negeri Gugus II Bukit Raya Kota Pekanbaru sebesar $54,59 \%$ dan termasuk pada kategori kurang baik, dan perlu ditingkatkan lagi sebagai mana dengan tujuan UKS yakni untuk meningkatkan mutu pendidikan dan prestasi belajar peserta didik dengan meningkatkan perilaku hidup bersih dan sehat, baik peningkatan kesehatan peserta didik maupun lingkungannya sehingga memungkinkan pertumbuhan dan perkembangan yang harmonis dan optimal dalam rangka pembentukan manusia Indonesia seutuhnya. (Tim Pembina UKS Pusat dalam Praditya \& Nasution, 2016, p. 42).

Menurunnya pelaksanaan UKS di sekolah mungkin dikarenakan tidak berjalannya pembinaan dan pengembangan UKS di sekolah. Seperti yang telah dikemukakan oleh Veugelers dan Angela dalam Fridayanti \& Prameswari (2016, p. 9) bahwa sekolah merupakan salah satu pihak yang turut berperan penting dalam memberikan pendidikan kesehatan bagi anak yang bertujuan untuk menanamkan kebiasaan hidup sehat bagi anak.

\section{SIMPULAN DAN SARAN}

\section{Simpulan}

Berdasarkan hasil penelitian dan pembahas-an dapat disimpulkan sebagai berikut: (1) aspek lingkungan kehidupan sekolah yang sehat dengan kategori cukup, (2) aspek pendidikan atau penyuluhan di sekolah dengan kategori kurang baik, (3) aspek pelayanan kesehatan di sekolah dengan kategori kurang baik. Secara kesulurahan dari ketiga aspek tersebut diperoleh hasil dengan kategori kurang baik. Dengan demikian dapat dinyatakan bahwa pelaksanaan program Trias UKS di SD Negeri Gugus II Bukit Raya Kota Pekanbaru kurang baik.

\section{Saran}

Berdasarkan kesimpulan hasil penelitian di atas, peneliti menyarankan sebagai berikut: (1) Kepala Dinas Pendidikan dan Kebudayaan perlu meningkatkan kerja sama dalam bidang peningkatan layanan khusus sekolah dengan instansi yang berkompeten dalam bidang kesehatan untuk meningkatkan pelaksanaan program Trias UKS yang lebih baik, (2) Pihak sekolah hendaknya meningkatkan jalinan kerja sama dengan puskesmas setempat dalam rangka pelaksanaan program Trias UKS yang lebih baik, dan (3) Guru pendidikan jasmani dan kesehatan agar mempertahankan UKS yang sudah berjalan dan dapat lebih memahami arti pentingnya UKS serta meningkatkan peranannya bagi peserta didik maupun semua anggota masyarakat sekolah.

\section{DAFTAR PUSTAKA}

Fridayanti, D. V., \& Prameswari, G. N. (2016). Peran UKS (usaha kesehatan sekolah) dalam upaya penanggulangan obesitas pada anak usia sekolah. Journal of Health Education, 1(2). Retrieved from https://journal.unnes.ac.id/sju/index.php/j healthedu/article/view/18787

Hadi, S. (1991). Analisis butir untuk instrumen. Yogyakarta: Andi Offset.

Hasan, R., \& Alatas, H. (2005). Ilmu kesehatan anak. Jakarta: FK UI.

Mukminin, A., \& Tasu'ah, N. (2016). Pengembangan model layanan program usaha kesehatan sekolah (UKS) terintegrasi pada lembaga pendidikan anak usia dini (PAUD) di Kota Semarang (Studi pada lembaga taman kanak-kanak di Kota Semarang). Jurnal Penelitian Pendidikan, 33(2), 117-126. https://doi.org/10.15294/jpp.v33i2.9094

Poernomo, S. (1979). Kesehatan sekolah di Indonesia. Jakarta: Yayasan Darma Bhakti.

Poernomo, S., Suharto, S., \& Siswanto, M. (2002). Usaha kesehatan sekolah (UKS). Jakarta: Departemen Kesehatan Republik Indonesia.

Praditya, D. K., \& Nasution, J. D. H. (2016). Survei pelaksanaan usaha kesehatan sekolah (UKS) dan peran guru pendidikan jasmani di SMP se-Kecamatan Mojowarno Kabupaten Jombang. Jurnal Pendidikan Olahraga Dan Kesehatan, 


\section{Jurnal Keolahragaan 6 (1), 2018 - 28}

Leni Apriani, Novri Gazali

4(1), 224-231. Retrieved from http://jurnalmahasiswa.unesa.ac.id/index. php/jurnal-pendidikanjasmani/article/view/17365

Sitepu, H., Ratag, G. A. E., \& Siagian, I. T. (2015). Peran serta masyarakat sekolah dalam pelaksanaan program usaha kesehatan sekolah di SMP Negeri 1 Manado. Jurnal E-Biomedik, 3(3), 798804. Retrieved from https://ejournal.unsrat.ac.id/index.php/ebi omedik/article/view/10147
Soenarjo, R. J. (2008). Usaha Kesehatan Sekolah. Bandung: PT Remaja Rosdakarya.

Sudijono, A. (2005). Pengantar statistik pendidikan. Jakarta: PT Raja Grafindo Persada.

Sugiyono. (2010). Metode penelitian kuantitatif kualitatif dan $R \& D$. Bandung: Alfabeta.

Trisnowati, T., \& Moekarto, M. (2007). Materi pokok pendidikan jasmani dan kesehatan. Jakarta: Universitas Terbuka. 